\title{
ĐỔI MỚI PHƯƠNG PHÁP ĐÀO TẠO THÍ́CH ỬNG VỚI NHU CẦU NHÂN LỰC NGÀNH KHÍ TƯợNG THỦY VĂN TẠI TRƯỜNG ĐẠI HỌC KHOA HỌC TỤ NHIÊN, ĐHQG HÀ NỘI
}

\author{
Công Thanh ${ }^{1}$, Nguyễn Quang Hưng ${ }^{1 *}$, Mai Văn Khiêm²
}

Tóm tắt: Trong thời kỳ cách mạng công nghệ 4.0 cũng nhu đối mặt với nhũng thách thức mới về yêu cầu công việc của ngành Khí tượng Thủy văn, công tác đào tạo nhân lực đòi hỏi có nhũng thay đổi thich úng sự thay đổi tù phía nhà tuyển dụng. Khoa Khi tuợng Thủy văn và Hải dưong hoc, trương Đại học Khoa học Tự nhiên, ĐHQGHN đã nhân thức được nhũng vấn đề đó trong đào tạo và chủ động tìm tòi, thay đổi phuoong pháp giảng dạy để đáp ứng với sụ phát triển của xã hội. Phưong pháp lấy người học làm trọng tâm được nghiên cứu xem xét và triển khai áp dụng trong giảng dạy và bước đầu cho nhũng kết quả khả quan. Sinh viên đã thay đổi thái độ với học tập theo chiều huớng tích cưc. Trong quá trình triển khai, một số vấn đề cũng đã được ghi nhận và có nhũng đề xuất cu thể để cho công tác đào tạo được hiệu quả hơn nũa.

Tù khóa: Người học làm trọng tâm, đào tạo, Khí tượng Thủy văn, Tổng cục Khí tượng Thủy văn.

Ban Biên tập nhận bài: 11/12/2019 Ngày phản biện xong: 12/12/2019 Ngày đăng bài: 20/12/2019

\section{Mở đầu}

Trong nhiều năm gần đây, thuật ngữ giảng dạy lấy người học làm trung tâm đang trở nên quen thuộc, đã được ghi nhận trong nhiều nghiên cứu của nước ngoài cũng như trong nước. Đối với giáo dục và đào tạo của Việt Nam, phương pháp đào tạo lấy người học làm trung tâm đã được nghiên cứu trong một số các trường sư phạm một cách nghiêm túc, rất nhiều các khóa đào tạo đã được xây dựng áp dụng phương pháp này và đều thu nhận những kết quả khả quan [1].

Vào những năm đầu thập kỷ 90, Kevin Bary và Len King (1998) [2] đưa ra các nhận định tổng kết về dạy học tại New Zealand và Úc, theo các tác giả thì những người đầu tiên đã tổng hợp đúc kết và hoàn thiện phương pháp dạy học lấy người học làm trung tâm là những công trình của Dewey (1938) [3] và Rogers và Freiberg (1994) [4]. Những nghiên cứu này đều đề cao nhu cầu, lợi ích của người học, đề xuất việc để cho người học lựa chọn nội dung học tập, được tự lực tìm tòi nghiên cứu, giáo viên sẽ chịu trách nhiệm hướng dẫn, gợi mở và giúp đỡ người học trong quá trình lựa chọn mục tiêu cũng như truyền thụ các kiến thức theo nhu cầu. Chính với các định hướng như vậy, khác với xu hướng truyền thống thiết kế chương trình dạy học lấy logic nội dung môn học và vai trò người dạy làm trung tâm thì ở phương pháp mới này $\mathrm{xu}$ hướng thiết kế chương trình học tập lại lấy nhu cầu, lợi ích của người học làm trung tâm. Tuy nhiên, phải khẳng định rằng như vậy không đồng nghĩa với việc người dạy sẽ đứng bên rìa của quá trình học tập.

Trong một số nghiên cứu khác, ngoài Dewey thì Jean Piaget và Lev Vygotsky cũng được vinh danh như những người tiên phong trong việc nghiên cứu đánh giá phương pháp lấy người học tập làm trung tâm. Các nhà nghiên cứu lý luận này đều có tư tưởng ủng hộ giáo dục tiến bộ, và

${ }^{1}$ Khoa Khí tuợng Thủy văn và Hải duong họ, Đại học Khoa hoc Tụ nhiên, ĐHQGHN,

${ }^{2}$ Trung tâm dụ báo Khí tượng Thủy văn Quốc gia, Tổng cuc Khí tượng Thủy văn

Email: hungnq@hus.edu.vn 
họ tin rằng học tập là một quá trình xã hội và kinh nghiệm. Họ cho rằng một môi trường lớp học trong đó học sinh có thể học cách suy nghĩ nghiêm túc và giải quyết các vấn đề trong thế giới thực là cách tốt nhất để chuẩn bị cho người học về tương lai. Ngoài ra, Rogers và Freiberg (1994) [5] đã nhận định sự định hình của mỗi cá nhân cũng đóng góp vào quá trình học tập lấy người học làm trung tâm, với câu phát biểu: "Việc học duy nhất ảnh hưởng đáng kể đến hành vi (và giáo dục) là tự khám phá”.

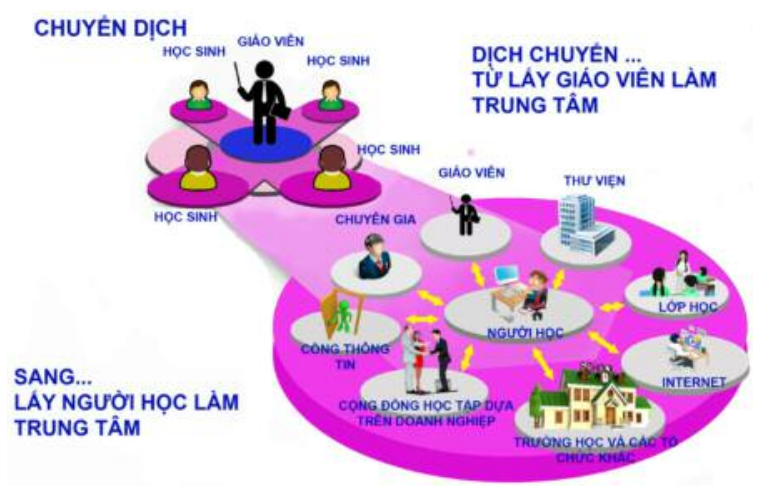

Hình 1. Dịch chuyển mô hình giáo dục tù̀ Giáo viên làm trung tâm sang Người học làm trung tâm

\section{Phương pháp giảng dạy lấy người học làm trung tâm}

Theo Trầm Bá Hoành (2003) [6], bản chất quá trình dạy học gồm hai mặt quan hệ hữu cơ: hoạt động dạy của giáo viên và hoạt động học của học sinh. Trong lí luận dạy học có những quan niệm khác nhau về vai trò của giáo viên và vai trò của học sinh nhưng tựu chung lại có hai hướng: hoặc tập trung vào vai trò hoạt động của giáo viên hoặc tập trung vào vai trò hoạt động của học sinh. Từ rất lâu trong ngành giáo dục của chúng ta đã có câu khẩu hiệu "Tất cả vì học sinh thân yêu", đó cũng là tư tưởng đã xem học sinh như một trung tâm của mọi hoạt động giáo dục trong nhà trường. Giáo dục nhà trường là một quá trình có mục đích, có kế hoạch, được tiến hành dưới sự chỉ đạo chặt chẽ của giảng viên.
Thực hiện ý tưởng lấy người học làm trung tâm không những không hạ thấp vai trò của giáo viên mà trái lại đòi hỏi giáo viên phải có trình độ cao hơn nhiều về phẩm chất và năng lực nghề nghiệp. Rassekh và Vaideneau (1987) [7] viết: "Với sự tham gia tích cực của người học vào quá trình học tập tự lực, với sự đề cao trí sáng tạo của mỗi người học thì sẽ khó mà duy trì mối quan hệ đơn phương và độc đoán giữa thày và trò. Quyền lực của giáo viên không còn dựa trên sự thụ động và dốt nát của học sinh mà dựa trên năng lực của giáo viên góp phần vào sự phát triển tột đỉnh của các em... Một sáng tạo là một GV biết giúp đỡ HS tiến bộ nhanh chóng trên con đường tự học. Giáo viên phải là người hướng dẫn, người cố vấn hơn là chỉ đóng vai trò công cụ truyền đạt tri thức". Tương tự như vậy, trong nghiên cứu của mình, Đào Hồng Thu (1996) [8] cũng đã đúc kết: "Khi học sinh đóng vai trò trung tâm trong quá trình dạy và học thì quá trình này là quá trình hoạt động tri thức sáng tạo. Ở đây, người thầy là người hướng dẫn và luôn luôn đi đầu trong mọi hoạt động sáng tạo của cả quá trình học tập."

Trong quá trình phát triển, kiểu dạy học lấy học sinh làm trung tâm ngày càng được chú ý so với kiểu dạy học lấy giáo viên làm trung tâm. Lê Khánh Bằng (1994) [9] đã đưa ra so sánh.

Như vậy có thể thấy, học tập lấy học sinh làm trung tâm có nghĩa là đảo ngược sự hiểu biết truyền thống của giáo viên về quá trình học tập và đưa học sinh vào trung tâm của quá trình học tập. Trong lớp học lấy giáo viên làm trung tâm, giáo viên là nguồn kiến thức chính. Mặt khác, trong các lớp học lấy học sinh làm trung tâm, học tập tích cực được khuyến khích mạnh mẽ. Thông qua tương tác ngang hàng, tư duy hợp tác có thể dẫn đến sự phong phú về kiến thức. Khi đặt một giáo viên gần với cấp độ ngang hàng, kiến thức và học tập được nâng cao, mang lại lợi ích chung cho học sinh và lớp học. 
Bảng 1. So sánh giữa phuoong pháp Người học làm trung tâm và Giáo viên làm trung tâm [9]

\begin{tabular}{|c|c|}
\hline Giáo viên làm trung tâm & Học sinh làm trung tâm \\
\hline I. Nội dung & I. Nội dung \\
\hline 1. Sự kiện, thông tin có sã̃n & 1. Các khái niệm, vấn đề \\
\hline II. Phương pháp & II. Phương pháp \\
\hline 2. Ghi nhớ & 2. Sự tìm tòi \\
\hline 3.Tập trung vào bài giảng & 3.Khám phá và giải quyết vấn đề \\
\hline 4. Người nghe thụ động & 4. Người học chủ động tham gia \\
\hline 5. Giáo viên chiếm ưu thế, có quyền lực & $\begin{array}{l}\text { 5. Giáo viên là người điều khiển, thúc đẩy, } \\
\text { tìm tòi }\end{array}$ \\
\hline III. Môi trường & III. Môi trường \\
\hline 6. Không khí lớp học hình thức, máy móc & 6. Tự chủ, thân mật, không hình thức \\
\hline $\begin{array}{l}\text { 7. Sắp xếp chỗ ngồi cố định, giáo viên chiếm } \\
\text { vị trí trung tâm }\end{array}$ & 7. Chỗ ngồi linh hoạt \\
\hline 8. Dùng kĩ thuật dạy học ở mức tối thiểu & $\begin{array}{l}\text { 8. Sử dụng thường xuyên các kĩ thuật dạy } \\
\text { học }\end{array}$ \\
\hline IV. Kết quả & IV. Kết quả \\
\hline 9. Tri thức có sẵn & 9. Tri thức tự tìm \\
\hline $\begin{array}{l}\text { 10. Trình độ phát triển nhận thức thấp, có hệ } \\
\text { thống. Chủ yếu là ghi nhớ }\end{array}$ & $\begin{array}{l}\text { 10. Phát triển cao hơn về nhận thức, tình cảm } \\
\text { và hành vi }\end{array}$ \\
\hline 11. Phụ thuộc vào tài liệu & 11. Tự tin \\
\hline 12. Chấp nhận các giá trị truyền thống & 12. Biết tự xác định các giá trị \\
\hline
\end{tabular}

\section{Hiện trạng đào tạo tại Khoa Khí tượng} Thủy văn và Hải dương học

Hiện nay, Khoa cung cấp nhân lực ở trình độ Đại học và sau đại học trong lĩnh vực khí tượng thủy văn. Các cơ sở đào tạo về lĩnh vực này với quy mô lớn trong nước có thể kể đến Đại học Khoa học Tự nhiên, Đại học Thủy lợi, Đại học Tài nguyên và Môi trường Hà Nội, Đại học Tài nguyên và Môi trường thành phố Hồ Chí Minh, Đại học Bách Khoa thành phố Hồ Chí Minh, Đại học Cần Thơ, Viện Khoa học Khí tượng Thủy văn và Biến đổi khí hậu. Riêng với chuyên ngành Khí tượng thì việc đào tạo hầu hết tập trung tại trường Đại học Khoa học Tự nhiên, Khoa Khí tượng Thủy văn và Hải dương học với bề dày hơn 20 năm thành lập và hơn 60 năm đào tạo. Khoa Khí tượng Thủy văn và Hải dương học thuộc trường Đại học Khoa học Tự nhiên, ĐHQG có 25 giảng viên trong đó gồm 2 giáo sư, 11 phó giáo sư, 4 tiến sĩ và 8 thạc sĩ đảm nhận giảng dạy cho cả ba chuyên ngành Khí tượng, Thủy văn và Tài nguyên nước và Hải dương học. Lượng giảng viên nói chung là đang ở mức tối thiểu theo quy định của Bộ Giáo dục và Đào tạo để tổ chức đào tạo. Ngoài ra, các giảng viên

cũng tham gia tích cực trong các nghiên cứu khoa học thông qua các đề tài cấp trường, cấp quốc gia hay các đề tài ứng dụng của Bộ, của tỉnh. Trong thời gian ngắn sắp tới, đội ngũ giảng viên sẽ gặp khó khăn về số lượng khi các thầy cô đến tuổi nghỉ hưu, trong khi khoảng cách giữa lớp các cán bộ sắp về hưu và lực lượng trẻ kế cận chưa được cân bằng. Để có thể duy trì và đẩy mạnh công tác đào tạo, việc xây dựng lực lượng kế cận đang là một nhiệm vụ hàng đầu của các cơ sở đào tạo, tuy nhiên ngay cả việc tuyển sinh viên mới ra trường hoặc thu hút các tiến sĩ tốt nghiệp ở nước ngoài về đều đang gặp nhiều trở ngại.

Con số sinh viên trung bình của toàn khoa trong vài năm gần đây là khoảng 300 sinh viên, và cung cấp cho xã hội khoảng 40 cử nhân ngành Khí tượng, 30 cử nhân ngành Khoa học và Công nghệ Biển, và 30 cử nhân ngành Thủy văn Tài nguyên nước.

Đối với đào tạo sau đại học, mỗi năm có khoảng 20-30 học viên cao học và 5 nghiên cứu sinh nhập học. Ngoài đào tạo, các công tác nghiên cứu khoa học cũng được chú trọng, mỗi năm các cán bộ Khoa tham gia chủ trì 1-2 đề tài 
dự án cấp quốc tế, 7-9 đề tài cấp quốc gia và 35 các đề tài với các Tỉnh. Số lượng công bố của Khoa mỗi năm đều đặn khoảng 40 bài báo trong nước và quốc tế, 20 báo cáo khoa học, như vậy mỗi cán bộ trong khoa có gần 9 công bố trong một năm, xếp hạng giữa trong số các khoa của trường Đại học Khoa học Tự nhiên.

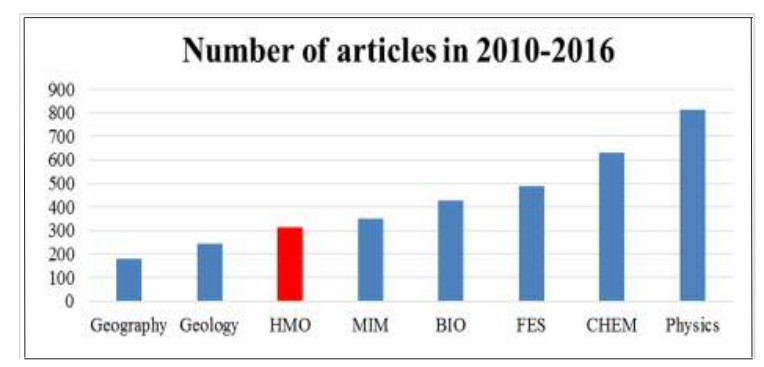

Hình 2. Số lượng công bố trung bình của các Khoa trong truòng Đại hoc Khoa hoc Tư nhiên, ĐHQGHN

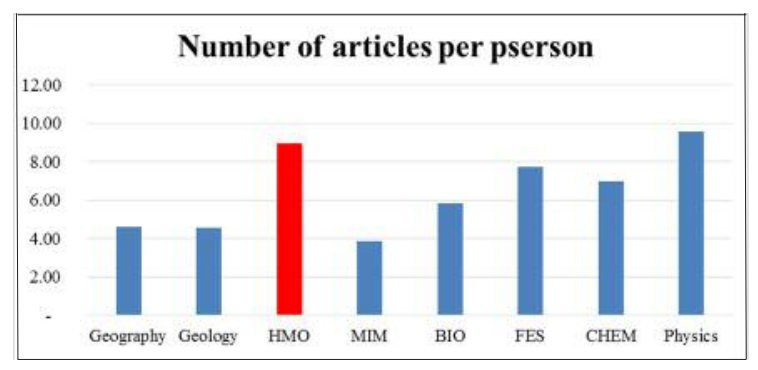

Hình 3. Số lượng công bố trung bình trên đầu người của các khoa trong Đại hoc Khoa hoc

\section{Tư nhiên}

Hướng đào tạo của Khoa đã được cập nhật theo trường bao gồm cả hai hướng ứng dụng và nghiên cứu khoa học cơ bản, tuy nhiên thực tế cho thấy cơ sở vật chất của ngành đào tạo Khí tượng Thủy văn được đầu tư rất hạn chế. Khoa chưa có phòng thí nghiệm đạt chuẩn quốc gia nào để phục vụ sinh viên. Các trang thiết bị thí nghiệm đo đạc hiện trường, thực hành có được trang bị nhưng không đồng bộ, nhiều trang thiết bị thiếu điều kiện để bảo quản và bảo dưỡng thường xuyên theo định kỳ. Các khung chương trình đào tạo của Khoa nói chung khá đầy đủ các học phần cơ bản và các học phần chuyên ngành và đều có các đợt cập nhật, xây dựng mới khung chương trình liên tục. Thời gian đào tạo theo quy định là 4 năm đối với bằng cử nhân, sinh viên cần hoàn thành từ 134 đến 140 tín chỉ để nhận được bằng, giữa các học kỳ đều có các đợt thực tập thực tế tại các đơn vị như các trạm quan trắc, đài Khí tượng Thủy văn, hay Trung tâm dự báo. Tuy nhiên, theo đánh giá từ phía các nhà tuyển dụng, còn một số khoảng cách cần xem xét và chỉnh sửa cập nhật giữa kiến thức giảng dạy với yêu cầu triển khai công việc thực tế trong ngành.

Trong vài năm gần đây, lượng thí sinh đăng ký vào các ngành Khí tượng Thủy văn đều giảm sút, thậm chí có nhiều cơ sở không tuyển được sinh viên. Điểm chuẩn xét tuyển nhiều trường Đại học đang ở mức trung bình khá tới trung bình nhưng vẫn không thu hút được nhiều sự quan tâm. Đầu vào thấp do đó quá trình đào tạo cũng càng khó khăn, nhiều sinh viên không xác định mục tiêu phấn đầu theo ngành ngay từ khi còn ngồi trên ghế nhà trường, chất lượng đào tạo bị ảnh hưởng nhiều. Khoa Khí tượng Thủy văn và Hải dương học cũng không nằm ngoại lệ của ảnh hưởng này. Có thể nói nguyên nhân của việc khó tuyển sinh một phần là do nhiều cơ quan trong ngành dọc đang thực hiện tinh giảm bộ máy nên nhu cầu tuyển dụng giảm, chế độ chính sách tiền lương còn thấp so với đặc thù công việc, các cơ chế chính sách đào tạo ngành Khí tượng Thủy văn chưa thực sự được quan tâm và chia sẻ các khó khăn nên rất khó để thu hút học sinh. Một phần nữa là các thông tin về đào tạo ngành nghề chưa được truyền bá rộng rãi, nên việc lựa chọn ngành học ban đầu của các em học sinh cấp 3 thiếu sự đánh giá đúng mực về ngành Khí tượng Thủy văn. Ngoài ra, trong quá trình đào tạo, có nhiều sinh viên chán nản, học tập đối phó hoặc nghỉ thi lại đại học, hoặc bỏ học vì chương trình học khá nặng, nhiều môn học vẫn giảng dạy theo các phương pháp truyền thống, ít được cập nhật, nặng về lý thuyết, dẫn đến học sinh học đuối và chán nản rồi bỏ dở. Đặc biệt, việc giảng dạy tại khoa hiện chỉ đạt hiệu quả thấp vì lý do thiếu sự đầu tư cơ bản về trang thiết bị phòng thí nghiệm và các máy móc để sinh viên có thể thực hành tại trường. Chính các nguyên nhân này dẫn đến việc khảo sát số sinh viên sau khi ra trường đi làm theo đúng chuyên ngành của luôn luôn dưới 40\%.

Tóm lại, có rất nhiều nguyên nhân dẫn đến việc ngành Khí tượng Thủy văn không thu hút được học sinh, số lượng sinh viên đào tạo ra trường giảm sút, số lượng sinh viên sau tốt 
nghiệp làm đúng chuyên ngành đào tạo lại càng giảm hơn nữa, dẫn đến việc tình trạng thiếu hụt nhân sự trong ngành Khí tượng Thủy văn trong vài năm tới sẽ trở nên trầm trọng. Nhận thức được vấn đề này, trong hàng loạt các giải pháp đưa ra như tăng cường công tác quảng cáo tuyển sinh, tăng cường tham gia nghiên cứu khoa học để thu hút đầu tư cơ sở hạ tầng cũng như đẩy mạnh phát triển nhân lực, xiết chặt chất lượng đào tạo và đánh giá sinh viên, đẩy mạnh hợp tác với các nhà tuyển dụng, kéo dài các đợt thực tập chuyên ngành tại các đơn vị trong ngành dọc, và đổi mới đào tạo, nâng cao chất lượng của sinh viên. Đổi mới phương pháp đào tạo, thu hút sự quan tâm chú ý của sinh viên, phát huy tính chủ động, đánh thức lòng yêu nghề, rèn luyện các kỹ năng mà vị trí công việc của ngành Khí tượng Thủy văn đòi hỏi là một trong những việc mà Khoa có thể chủ động triển khai và thực sự là một biện pháp đáng quan tâm để có những ghi chép, đánh giá cụ thể, nhằm phổ biến lại kinh nghiệm, thay đổi chỉnh sửa sao cho mang lại hiệu quả nhất.

\section{4. Đổi mới với phương pháp lấy người học làm trọng tâm}

Như đã phân tích ở trên, đây là phương pháp giảng dạy đặt học sinh, sinh viên vào vị trí trung tâm của giáo dục. Phương pháp dạy học này bắt đầu với việc tìm hiểu các môi trường giáo dục liên quan mà sinh viên xuất phát. Khoa đã triển khai liên tục các đợt khảo sát về sinh viên khi nhập học, các thông tin về trường cấp 3 , địa phương của sinh viên đều được thu thập, sau đó dựa trên các buổi làm việc của giáo viên chủ nhiệm với các học sinh để hiểu rõ các phương pháp học, thói quen của từng học sinh trong lớp, qua đó có thể điều chỉnh cách tiếp cận khi giảng bài. Rõ ràng, có rất nhiều học sinh khi bước chân vào giảng đường đại học đều bỡ ngỡ với cách học tập ở mức đại học, mất một thời gian để làm quen với cách học tập mới, khi phải chủ động nhiều hơn, đọc và tìm tài liệu nhiều hơn.

Trong các giờ giảng, Khoa đã yêu cầu các giáo viên dành một thời lượng nhỏ cuối buổi để cùng đánh giá mức độ tiếp thu bài giảng của sinh viên. Việc giảng viên đưa ra các mục tiêu học chi tiết cho từng giai đoạn và hướng dẫn sinh viên cùng đánh giá tiến độ học của học viên sẽ giúp cho người học có được các kỹ năng cơ bản để học tập. Phương pháp này tạo cho sinh viên nền tảng cho việc học, sinh viên tự sẽ có trách nhiệm với việc học của bản thân, tự đánh giá nhìn nhận được khả năng của mình, tiến độ của mình và nhận thức được mình cần điều chỉnh những gì để đạt được mục tiêu môn học.

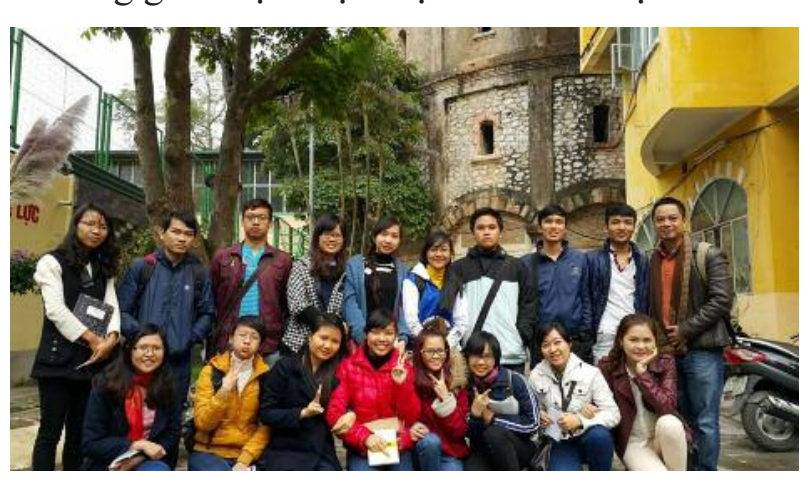

Hình 4. Thầy và trò K56TV trải nghiệm thực tế môn học Các phuoong pháp xủ lý nuớc tại Xí nghiệp kinh doanh nước sạch quận Hoàn Kiếm

Với phương pháp này giảng viên đóng vai trò là người hướng dẫn sinh viên trong quá trình học. Phương pháp giảng dạy người học là trung tâm mang đến nhiều lợi ích, trước hết nó loại bỏ cách dạy và học: Giảng viên đọc giáo án, sinh viên cắm cúi chép. Việc giảng dạy tại trường Khoa học Tự nhiên đã được hỗ trợ mạnh mẽ từ cấp trường nên đa số các phòng đều sử dụng máy chiếu, các phòng học thông minh còn có những dụng cụ hỗ trợ tối tân hơn nhiều, do đó, tương tác giữa thầy vào trò được khuyến khích và có môi trường để phát triển. Trong giờ giảng, các giáo viên sẽ liên tục đặt câu hỏi để nắm được khả năng tiếp thu bài của sinh viên, hoặc đặt các câu hỏi gợi mở để sinh viên tự tìm hướng ưa thích, hoặc đặt các câu hỏi để sinh viên tự tư duy đặt mình vào vị trí của người giảng. Bài giảng lúc nào rõ ràng sẽ phải chuẩn bị mở hơn, nhưng ngược lại, không đòi hỏi quá chi tiết, do đó các giảng viên cũng không nhất thiết phải tăng thời lượng dành cho chuẩn bị giáo án. Các làm này cũng khuyến khích sự sáng tạo từ giảng viên và sinh viên một cách tối đa, đồng thời tạo nên sự thân thiện giữa giảng viên và sinh viên thông qua việc tăng cường trao đổi, học hỏi qua lại.

Trước đây, trong rất nhiều giờ học, các sinh viên mệt mỏi, buồn ngủ, không tập trung, thậm chí làm việc riêng. Nhưng từ khi các giảng viên 
triển khai phương pháp người học là trung tâm thì rõ ràng với việc tương tác liên tục của thầy giáo đến sinh viên cũng như các câu hỏi kích thích suy nghĩ của sinh viên đã làm cho lớp học trở nên nhiệt tình hơn, sinh viên chủ động hơn trong suốt quá trình khám phá tìm tòi. Việc thay vì kiểm tra viết bằng những bài tập nhóm có trình bày cũng tạo cho sinh viên thói quen trình bày, đặt câu hỏi, tranh luận, phân tích, bảo vệ các ý kiến sáng tạo của mình. Việc giảng dạy theo phương pháp này không có nghĩa là với mỗi sinh viên sẽ có một yêu cầu riêng hay một giáo án riêng, mà các giáo án sẽ được chuẩn bị ở dạng mở hơn, kiến thức rộng hơn, và giảng viên sẽ tạo điều kiện cho mỗi sinh viên có thể tìm tòi hướng yêu thích của mình và cung cấp những kiến thức để các bạn khám phá. Giờ học có phân hóa theo trình độ và năng lực cho các sinh viên, tạo điều kiện thuận tiện cho các sinh viên bộc lộ và phát triển tiềm năng của mỗi bạn.

Việc học chịu ảnh hưởng rất nhiều từ các mối quan hệ giao tiếp với mọi người xung quanh, rất rõ ràng thấy nếu người học có cơ hội tiếp xúc với những người khác, học hỏi, thừa hưởng những kinh nghiệm đi trước, không chỉ như vậy mà nó còn làm cho tác phong làm việc linh hoạt, phản xạ tốt hơn trong nhiều tình huống giao tiếp với nhiều người khác nhau. . Các môi trường học cho phép tạo ra các mối tương tác xã hội, tôn trọng tính đa dạng, khuyến khích lối tư duy linh hoạt. Qua việc tiếp xúc và hợp tác với giáo viên hướng dẫn, cá nhân người học sẽ có cơ hội tiếp thu nhận thức và tư duy phản ánh, từ đó phát triển trình độ hiểu biết và hoàn thiện bản thân. Khoa liên tục tổ chức các buổi giao lưu giữa sinh viên với các cán bộ làm việc trong ngành, tổ chức các buổi thực địa theo các dự án để sinh viên tham gia (Hình 4), hoặc các đợt thực tập tại các trạm quan trắc hoặc các cơ quan trong ngành dọc Khí tượng Thủy văn.

Cuối cùng, Khoa đã đề nghị các giảng viên trong quá trình giảng bài đan xen lồng vào những kiến thức là các hiểu biết về vị trí việc làm, yêu cầu công việc sau này của sinh viên sau khi ra trường. Bản chất chiến lược của việc này là để sinh viên phải biết được sau khi học xong, cần đạt được những tiêu chuẩn nào, các kiến thức nào cần làm chủ, các kỹ năng nào phải thành thạo, để có thể đảm nhận được công việc ở vị trí mà mình đang mong muốn hướng tới. Đó cũng chính là cách khơi gợi để sinh viên tạo ra các mục tiêu cho bản thân và theo đuổi các mục tiêu đó. Khởi đầu, các mục tiêu ngắn và việc học có thể sơ sài trong một phạm vi nào đó nhưng qua thời gian, mức độ hiểu biết của học viên có thể được xác định thông qua trình tự tìm hiểu, trao đổi và tích luỹ các tri thức cần thiết.

Quá trình thay đổi hướng giáo dục lấy người học làm trọng tâm được một số thầy cô trẻ trong Khoa đang triển khai và có những biểu hiện khả quan, tích cực đối với sinh viên. Có rất nhiều sinh viên sau những đợt đi thực tập về có thái độ tích vực với môn học, ngành học, nhiều bạn sinh viên thể hiện trong các báo cáo thời gian đi thực tế lại hiểu bài và thu được nhiều kiến thức hơn là học trên giảng đường. Các kết quả này đang được ghi nhận và Khoa sẽ cần phải tìm hiểu về các phương pháp đánh giá, để triển khai một cách nghiêm túc và có những nhận định chuẩn xác, và xác định có triển khai đồng bộ trong toàn Khoa hay không. Tuy nhiên, để thay đổi các phương pháp, nhận thức về quá trình dạy học, để nâng cao chất lượng đầu ra của sinh viên, còn nhiều phương pháp khác được triển khai đồng thời.

\section{4. Đề xuất thực hiện}

Trong quá trình triển khai công tác đổi mới phương pháp giảng dạy, Khoa nhận thấy cần thiết có sự phối hợp chặt chẽ của các đơn vị trong ngành để đạt được hiệu quả cao nhất. Các đơn vị thuộc Tổng cục Khí tượng Thủy văn sẽ là những đơn vị ưu tiên nhất với các lý do: Là những đơn vị đã có quá trình phối hợp chặt chẽ trong đào tạo và nghiên cứu khoa học, cũng là những nhà tuyển dụng tương lai để tiếp nhận nguồn nhân lực đào tạo. Các đơn vị này sẽ phối hợp trong các công tác: Triển khai nghiên cứu khoa học chung, hội thảo hội nghị, đào tạo nâng cao các cán bộ trong ngành (sau đại học và các khóa học nâng cao), hỗ trợ thực tập và làm đề tài tốt nghiệp, chia sẻ dữ liệu và thông tin. Trong quá trình xây dựng khung chương trình cũng như đề cương chi tiết các học phần, các nhà tuyển dụng cần đóng góp các ý kiến, yêu cầu để giảng viên đưa các kiến thức cần thiết vào trong giảng dạy, xác định đúng chuẩn đầu ra cho mã ngành 


\title{
BÀI BÁO KHOA HỌC
}

đào tạo phù hợp với vị trí việc làm.

Đổi mới phương pháp giảng dạy, đồng nghĩa với việc sẽ cần đổi mới cả tư duy và giáo án, giáo trình, vì vậy, đối với các giảng viên, Trường và ngành cũng cần có sự quan tâm chú ý, dành thời gian và có chương trình/chính sách cụ thể để xây dựng/cập nhật bải giảng cũng như giáo trình. Song song với việc đầu tư nâng cao năng lực, việc đầu tư về cơ sở hạ tầng, trang thiết bị dụng cụ giảng dạy cũng là điều cấp thiết. Các thiết bị máy móc thí nghiệm, giáo cụ, internet giảng đường để phục vụ tương tác thầy và trò là những ưu tiên trước mắt.

Ngoài ra, không chỉ đổi mới phương pháp giảng dạy, điều thực sự cần làm là nhà nước cần có các chính sách cụ thể hơn với ngành Khí tượng Thủy văn, hiểu được các đặc trưng của ngành để có các hỗ trợ cần thiết, cho sinh viên an tâm theo học và xác định tương lai.

\section{Tài liệu tham khảo}

1. http://hocvienhaucan.edu.vn/hieu-qua-giang-day-tieng-anh-theo-phuong-phap-tich-cuc-laynguoi-hoc-lam-trung-tam-o-trung-tam-ngoai-ngu-tin-hoc-3249.html

2. Barry, K., King, L., (1998), Beginning teaching and beyond. 3rd ed. South Melbourne: Cengage Learning, pp. 686.

3. Dewey, J., (1938), Experience \& Education. New York, NY: Kappa Delta Pi, pp. 91.

4. Rogers, C.R., Freiberg, H.J., (1994), Freedom to Learn. Merrill, pp. 406.

5. Cari, C., Pamela, D., d'Angelo, S., (2014), Pedagogies for Student-Centered Learning: Online and On-Ground. Augsburg Fortress Publishers, ô. 126.

6. Trần Bá Hoành (2003), Tạp chí Thông tin khoa học giáo dục, 96/2003, 1.

7. Rassekh, S., Vaideneau, G., (1987), Les contenus de I'éducation - Perspectives mondiales d'ici a I'an 2000. UNESSCO, Paris, pp. 311.

8. Đào Hồng Thu (1996), Về vấn đề dạy học lấy học sinh làm trung tâm, T/T Công trình khoa học, ĐHBK Hà Nội, 17-23.

9. Lê Khánh Bằng (1994), Tài liệu hướng dẫn nghiên cứu và tham khảo về phuơng pháp dạy học ở đại học và công nghệ dạy học.

\section{INNOVATING EDUCATION METHOD TO ADAPT TO THE HUMAN RESOURCES NEEDS OF METEOROLOGY AND HYDROLOGY AT HANOI UNIVERSITY OF SCIENCE, VNU$$
\text { Cong Thanh }{ }^{1} \text {, Nguyen Quang Hung }{ }^{1 *} \text {, Mai Van Khiem }{ }^{2}
$$ \\ ${ }^{1}$ Faculty of Meteorology, Hydrology, and Oceanography, VNU University of Science, \\ Vietnam National University, Hanoi \\ ${ }^{2}$ National Centre for Hydro-Meteorological Forecasting, \\ Viet Nam Meteorological and Hydrological Administration}

\begin{abstract}
During the 4.0 technology revolution period as well as facing new challenges in the work requirements of the Meteorology and Hydrology industry, the education task also requires updated changes to keep up with the new challenge from employers. Faculty of Meteorology, Hydrology and Oceanography, VNU University of Science has been aware of this and actively exploring, changing consciousness and teaching methods to respond to transformation of society. The learnercentered approach has been studied, tested and implemented in teaching and has begun to produce positive results. Students have changed their attitude to learning in a positive way. During the implementation process, a number of issues were also noted and specific proposals were made to make the training more effective.
\end{abstract}

Keywords: Learners-centered, Education, Hydrometeorology, Vietnam Meteorological and Hydrological Administration. 